Article

\title{
Optimum Design of Hybrid Renewable Energy System for Sustainable Energy Supply to a Remote Island
}

\author{
Sajid Ali ${ }^{1,2}$ and Choon-Man Jang ${ }^{1,2, *}$ \\ 1 Smart City Construction Engineering, University of Science \& Technology (UST), 217, Gajeong-ro, \\ Yuseong-gu, Daejeon 34113, Korea; sajid_ali@kict.re.kr \\ 2 Department of Land, Water and Environmental Research, Korea Institute of Civil Engineering and Building \\ Technology (KICT), Daehwa-dong 283, Goyangdae-Ro, Ilsanseo-Gu, Goyang-Si, Gyeonggi-do 10223, Korea \\ * Correspondence: jangcm@kict.re.kr; Tel.: +82-31-910-0494
}

Received: 21 January 2020; Accepted: 5 February 2020; Published: 10 February 2020

\begin{abstract}
Renewable energy technologies can not only help in mitigating the greenhouse gas (GHG) emissions but it can also be very useful for electricity generation at remote locations, where no other means of power are available. The present study focuses on the techno-economic optimum design of a small hybrid renewable energy system (HRES) consisting of wind-solar as primary energy sources. The HRES was modelled for a remote island (Deokjeok-do Island, South Korea) using real electricity consumption data for one complete year. A daily mean load of $24,720 \mathrm{kWh}$ was entered at Deokjeok-do Island with a peak load of $2291.54 \mathrm{~kW}$. Average annual values of wind speed and daily solar radiations were estimated to be $3.6 \mathrm{~m} / \mathrm{s}\left(10 \mathrm{~m}\right.$ height) and $4.13 \mathrm{kWh} / \mathrm{m}^{2}$, respectively. A total of 8760 simulations were performed to achieve the hourly load demand of the mentioned island. In order to deal with the surplus and electricity deficit, two different types of energy storage systems (ESS) were modelled i.e., battery and pumped hydro storage (PHS). Four different HRESs were also evaluated as the most suitable based on levelized cost of energy (LCOE) and net present cost (NPC). A detailed economic break-down of each component and the impact of different sensitivity variables on decision making have also been discussed in detail.
\end{abstract}

Keywords: hybrid renewable energy system (HRES); energy-economics; energy storage system (ESS); levelized cost of energy (LCOE); net present cost (NPC); sustainable assessment

\section{Introduction}

With the rapid increase in the population of the world over the last few decades, it has now become a serious challenge for governments and energy policymakers to fulfil the electricity requirements of the majority of the people. According to the international energy agency (IEA), 1 out of 5 people in the world had no access to electricity until 2010 [1]. Most of the people having no access to electricity live in remote areas, such as villages and islands. One of the solutions is main grid extensions to such remote areas, but, for locations which are quite a far from main areas, this solution is not a feasible choice, not only from a technical point of view but economically as well. So, one of the best alternatives is to build an independent electricity production unit at such sites consisting of locally available renewable energy resources such as wind and solar [2-6].

Starting at now, numerous relevant examinations of presenting HRES at a remote territory have been driven far and wide. For instance, A.P. Navarro et al. [7] arranged a blend structure involving biomass and wind to plan a power plant with a limit of $40 \mathrm{MW}$ in Spain. Beside the guideline framework, their organized HRES moreover involved various parts, for instance, extra generators, ESS and biogas generators too. H. Borhanazad et al. [8] completed an examination to analyze the 
breeze qualities, sun controlled radiations and hydro ability of different territories in Malaysia for commonplace zap. M. Jibran et al. [9] surveyed the biomass capacity of Pakistan and expressed that biomass can produce $24 \%$ of the total electricity demand of the country. They thought about biomasses, for instance, city strong waste (MSW), bagasse and local creatures compost in their assessment. Binayak B. et al. [10] thought about an extraordinarily commendable model of HRES for town zap, containing wind-PV-hydro as fundamental vitality sources. They showed that presenting such HRESs at remote zones can be monetarily more affordable when contrasted with customary assets of vitality, for example, atomic. Mazzola et al. [11] organized a PV-biomass based HRES for a network in India and coordinated its money related probability too. The creators referenced that LCOE can be reduced up to $40 \%$ at whatever point differentiated and analyzed against power age from diesel generators. Furthermore, Jameel A. et al. [12] analyzed the HRES involving wind-PV-biomass as fundamental vitality hotspots for a network in Pakistan called the Kallar Kahar. The examination was driven for various conditions and analysts proposed the foundation of HRES near recently referenced site dependent on strong moderate financial outcomes.

South Korea is one of such countries which has a large number of islands within its territory. Most of these islands are connected with a central grid for fulfilling electricity requirements. However, there are also few islands which are situated at quite a large distance from the mainland, making it impossible to connect them with a central grid. One of such islands is Deokjeok-do Island (latitude: $37.22^{\circ}$, longitude: $126.15^{\circ}$ ), which is situated at a distance of almost $50 \mathrm{~km}$ from Incheon seaport. Currently, most of the electricity being generated here comes from fossil fuels but the government intends to make the mentioned island, along with other nearby islands, $100 \%$ diesel-free. In the present study, an independent and off-grid hybrid renewable energy system (HRES) is designed and optimized to supply the environmental-friendly energy for the island.

There are a number of studies that have been conducted recently in order to determine the feasibility of installing HRES in remote areas of South Korea. For instance, S. Baek et al. [13] considered Busan, a large metropolitan city in South Korea, for developing an optimal renewable energy power generation system. The study used the electricity consumption data of Busan City for the year 2013 and performed multiple scenario-based case studies. They considered only wind and solar as primary energy sources and found that the lowest LCOE corresponded to a value of approximately $0.399 \$ / \mathrm{kWh}$ with 100\% renewable energy fraction (REF). In another empirical study, S. Baek et al. [14] designed renewable energy power systems for the largest international airport of South Korea i.e., Incheon international airport. The authors' used current load (100\% load), $120 \%$ load and $140 \%$ load as the base input values for three different scenarios, respectively. On the basis of economic parameters such as LCOE and NPC, the authors stated that all the electricity requirements of the mentioned airport can be fully covered by renewable energy only.

Similarly, S. Baek et al. [15] also designed an optimal HRES for an emerging island of South Korea known as Yeongjong Island. This small island has critical importance in the economy of South Korea as the Incheon international airport is situated on this island. The authors strongly recommended the installation of HRES consisting of 11 Generic $10 \mathrm{~kW}$ wind turbines and $357 \mathrm{~kW}$ of PV panels with LCOE of $0.545 \$ / \mathrm{kWh}$ and NPC corresponded to almost 3.51 million USD. A very similar study was also performed by H. Kim et al. [16] focusing on Jeju Island, the largest island in South Korea. The authors generated multiple scenarios under two major categories i.e., grid-connected and off-grid power generation systems. They found that a grid-connected HRES will be the most suitable for Jeju Island consisting of PV-wind-battery-converter with the lowest LCOE. E. Park and S. J. Kwon [17] suggested a novel method to use HRES for powering electric-powered (EP) taxis in Daejeon, South Korea. They came up with the three most suitable (lowest LCOE and highest REF) HRESs for this purpose: most reliable case (grid-connected) with LCOE 0.425\$/kWh and REF 0.82, most optimal case (grid-connected) with LCOE $0.180 \$ / \mathrm{kWh}$ and REF 0.79 , and most optimal off-grid case with LCOE 0.461\$/kWh and REF 1.0. Similarly, E. Park and S. J. Kwon [18] and K. Yoo et al. [19] also suggested an 
optimal, independent HRES for Gadeokdo Island and Ulleungdo Island in South Korea, respectively. Some of the other case studies are also prominent in this regard for South Korea [20,21].

\subsection{Concept of Hybrid Renewable Energy System (HRES)}

Hybrid renewable energy system (HRES) or simply, renewable energy system comprises of at least two types of renewable energy resources such as wind potential and solar potential. The main idea about the concept of HRES is to supply cheap and sustainable electricity to areas especially quite away from mainland. HRES may be connected to the main power station or it can also be a separate electricity generation system, with its own system for dealing with excess electricity. Figure 1 shows the conceptual design of a typical HRES in which pumped hydro storage (PHS) is being used as an energy storage system (ESS). There are three types of energy sources mentioned in Figure 1, wind, solar and water stored at a particular height. One of the advantages of such HRES is also that it can utilize rainwater very efficiently to produce electrical power. As shown in Figure 1 that rainwater can be stored in the upper reservoir (UR) and then it can be allowed to run down to rotate the hydro turbine rotor for producing electrical power. Lower reservoir (LR) collects the water and pump stores it back into the UR [2-6].

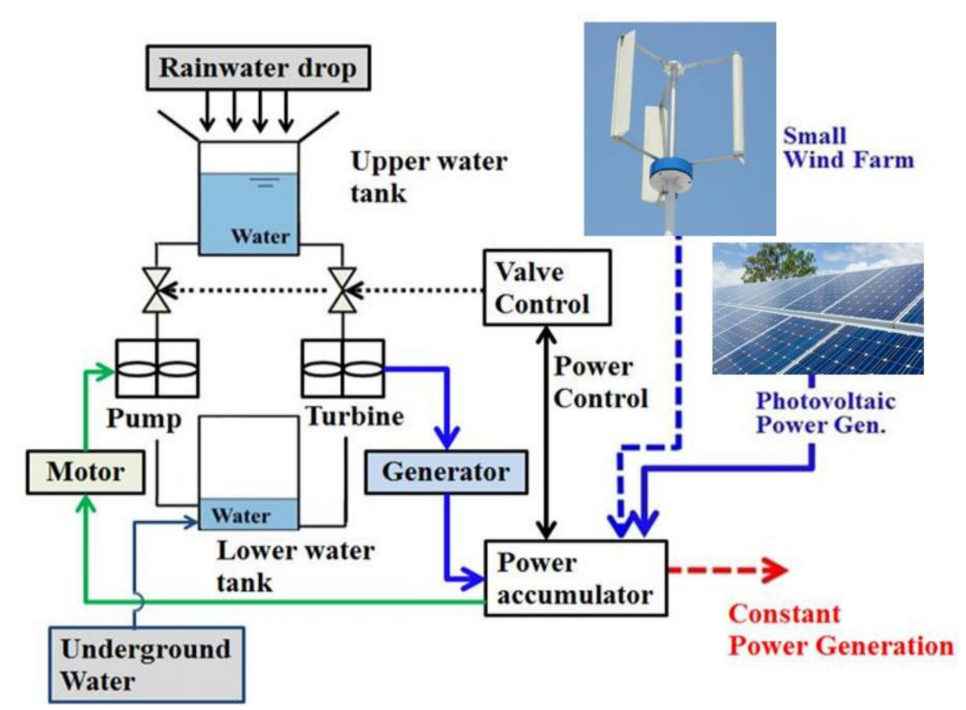

Figure 1. Conceptual design of a typical hybrid renewable energy system (HRES) [22].

The main objectives of the current work include:

- Studying the feasibility of designing small HRES consisting of wind and solar as primary energy sources. The intended capacity of small HRES is $1 \mathrm{MW}$.

- Designing PHS for storing surplus electricity

- Comparing PHS with batteries on economic grounds

- Investigating multiple scenario-based cases of HRES on the basis of detailed techno-economic analysis.

\subsection{Profile of Deokjeok-Do Island, South Korea}

Deokjeok-do is an island in South Korea, situated $45 \mathrm{~km}$ away from Incheon City. The total area of Deokjeok-do Island is almost $21 \mathrm{~km}^{2}$ with a population over 17,000. This island is too far from the mainland of the country, therefore it is not economically feasible to connect this place with a grid in order to supply electricity. Therefore, Deokjeok-do generates its own electricity using diesel fuels, but recently, the local administration has shown its interest to make Deokjeok-do, a green island in terms of electricity generation. This study analyzes the available renewable energy potential at the local site 
and then suggests an optimal HRES based on economic evaluations. Figure 2 shows the geographical location of Deokjeok-do Island.

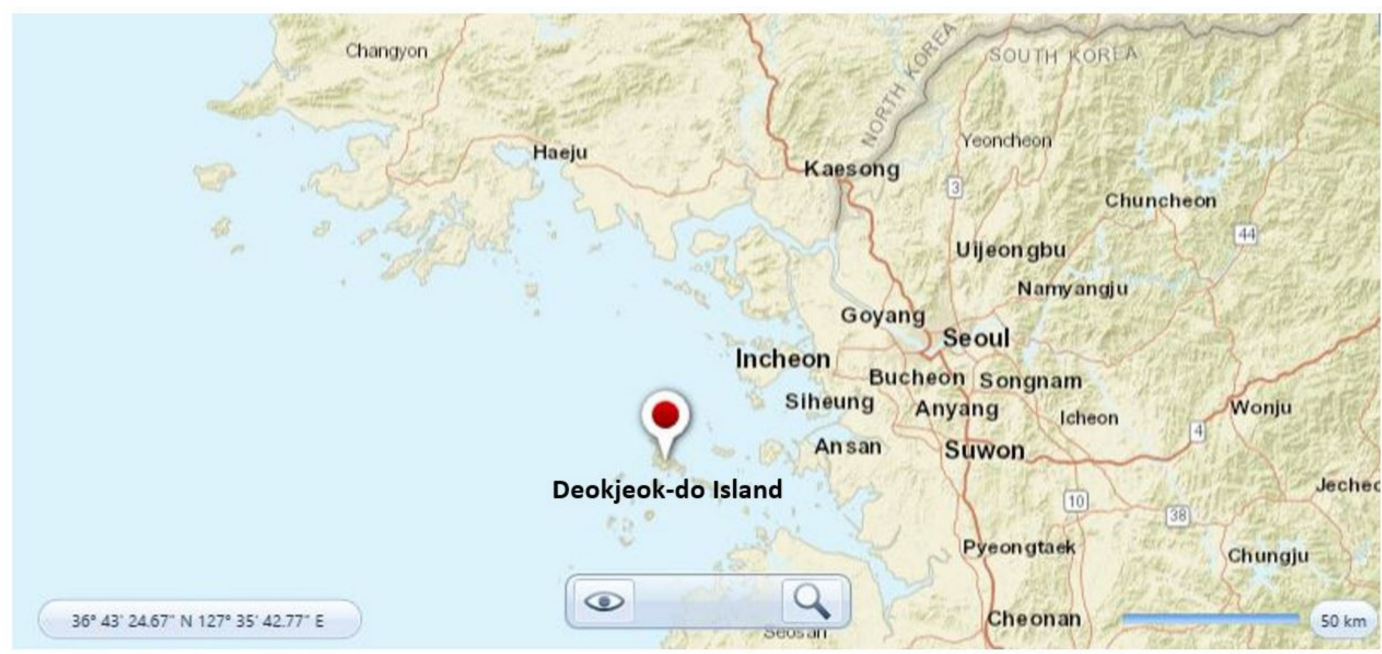

Figure 2. Location of Deokjeok-do Island in South Korea.

Although small HRES can also integrate other renewable energy resources such as tidal, biomass and food-waste along with just wind-solar nexus. All of these resources are available at the studied site but due to the unavailability of such data, these technologies were not considered in the current study and only wind-solar were investigated.

\section{Materials and Methods}

This section presents some of the important details about Deokjeok-do Island such as electric load and the potential of available renewable energy sources.

\subsection{Assessment of Electricity Consumption}

So, as to ideally plan an HRES, electricity data, for example, top load, day by day normal power utilization and hourly consumption profile are of basic significance. The easy-accessibility of electricity data empowers planning a progressively optimal HRES.

Figure 3 demonstrates the month to month power utilization at Deokjeok-do [23]. The mean daily burden was observed to be roughly $24,720 \mathrm{kWh}$ with pinnacle heap of $2292 \mathrm{~kW}$ regularly happening during the winter season, and complete yearly power utilization approaches to an estimation of 7.3 GWh. The power utilization in winter is much larger than other seasons because of the frequent utilization of room warming facilities fueled by electric power.

\subsection{Estimation of Renewable Energy Potential}

The present study will consider only two renewable energy sources namely wind and solar. The potential of each source will be estimated and how it can affect the power production, is analyzed at first.

\subsubsection{Wind Resources Assessment}

The authors [22] have studied the wind characteristics at Deokjeok-do and found that most of the winds are coming from the south-west with an average wind speed of $3.6 \mathrm{~m} / \mathrm{s}$ at a $10 \mathrm{~m}$ height. There are two important statistical parameters needed to be estimated while analyzing the wind potential, 
called the Weibull probability density function (PDF) and cumulative distribution function (CDF), respectively and can be defined mathematically as:

$$
\begin{gathered}
P D F=f(v)=\left(\frac{k}{c}\right)\left(\frac{v}{c}\right)^{k-1} \exp \left[-\left(\frac{v}{c}\right)^{k}\right](v>0 ; k, c>0) \\
C D F=F(v)=1-\exp \left[-\left(\frac{v}{c}\right)^{k}\right]
\end{gathered}
$$

where, $k, c$ and $v$ are Weibull shape parameter, Weibull scale factor and wind speed, respectively. $k$ determines the $x$-axis of Weibull distribution whereas $c$ determines the $y$-axis. The accurate estimation of these two important parameters is of critical importance. There are a lot of methods to estimate these variables but the empirical method will be deployed in the current study due to its accuracy and robustness [22]. In the following equations, $v_{m}$ is mean wind speed, $n$ is number of wind data, $\sigma$ is the standard deviation and $\Gamma$ is called gamma function.

$$
\begin{gathered}
v_{m}=\frac{1}{n}\left[\sum_{i=1}^{n} v_{i}\right] \\
\sigma^{2}=\frac{1}{n-1} \sum_{i=1}^{n}\left(v_{i}-v_{m}\right)^{2} \\
k=\left(\frac{\sigma}{v_{m}}\right)^{-1.086}(1 \leq k \leq 10) \\
c=\frac{v_{m}}{\Gamma\left(1+\frac{1}{k}\right)}
\end{gathered}
$$

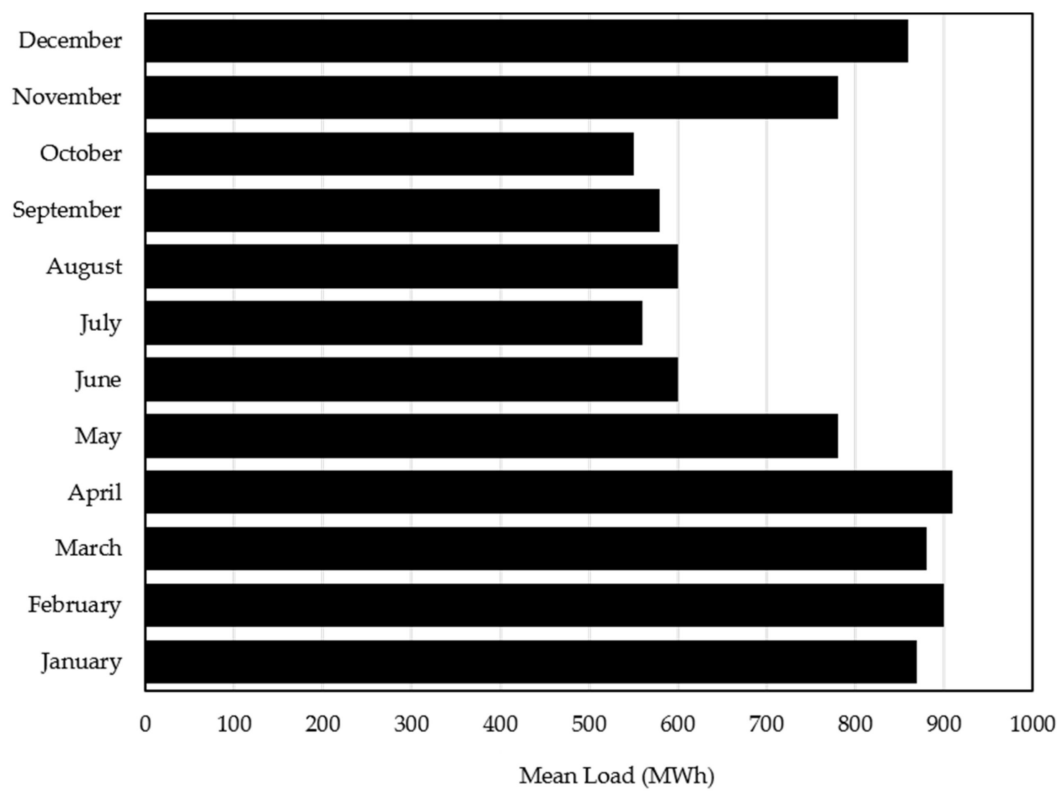

Figure 3. Monthly electric load at Deokjeok-do Island [23].

Figure 4 shows the wind characteristics of Deokjeok Island prepared using wind data (2005-2015) measured at $10 \mathrm{~m}$ height as measured by Korean Metrological Administration (KMA) [24] and analyzed by the authors [22]. The most frequent wind speed is $4 \mathrm{~m} / \mathrm{s}$ as shown in Figure $4 \mathrm{~b}$. 


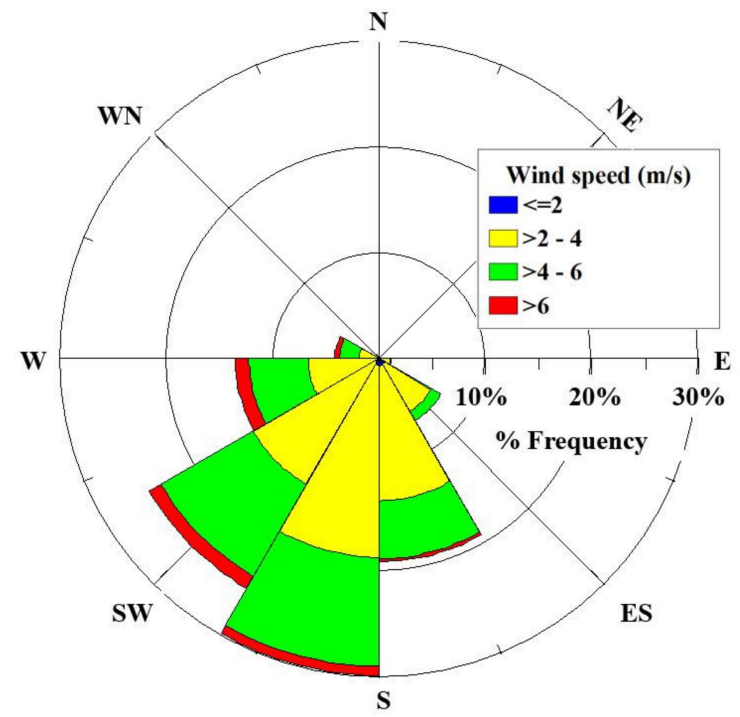

(a)

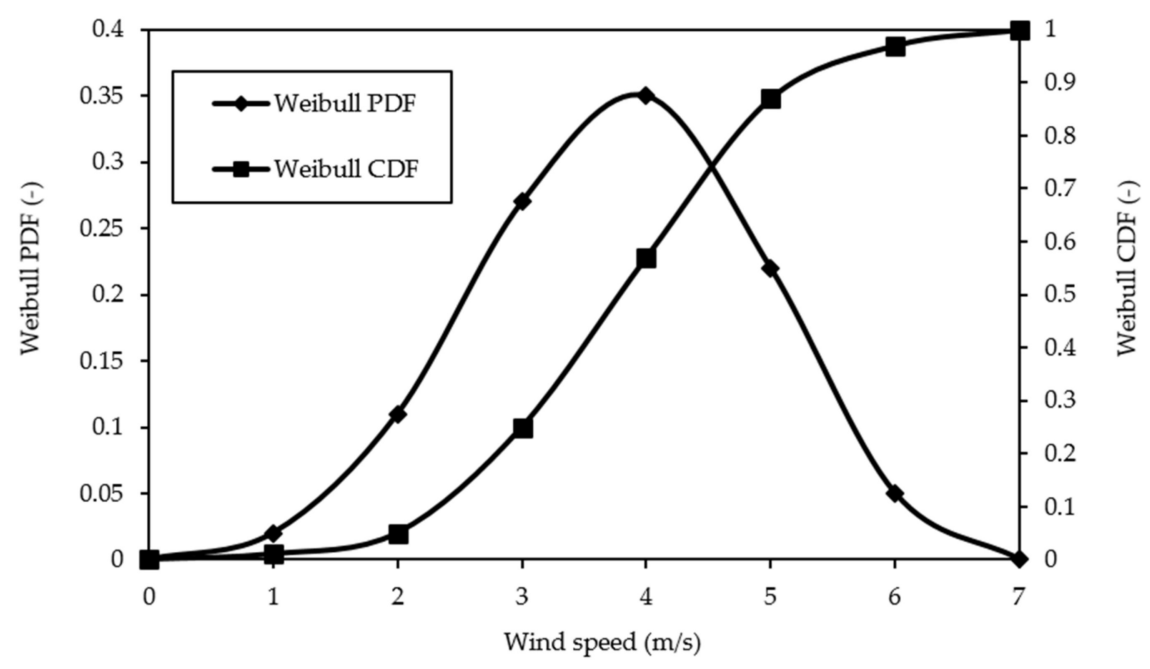

(b)

Figure 4. Wind conditions at Deokjeok-do Island (a) Wind rose (b) Weibull plot [22].

\subsubsection{Solar Resources Assessment}

A study conducted by O. Nematollahi and K.C. Kim [25] estimated the solar potential over different parts of South Korea. The authors used 24 locations to cover the whole country and stated the monthly radiation and clearness index of each of the 24 locations. The solar data used by them were collected for five years (2011-2015) and originally recorded by Korean meteorological administration (KMA). The authors averaged out all the five years of data and reported the final results. The present study will use, the results of O. Nematollahi and K.C. Kim [25] to estimate the solar resources of Deokjeok-do Island. Out of these 24 locations, Incheon City is the nearest to Deokjeok-do Island, therefore solar radiations over Incheon city will be considered identical as over Deokjeok-do Island because of the facts that data were averaged out for five years.

Figure 5 shows the estimated solar radiations over Deokjeok-do Island used as input for HOMER pro simulations. 


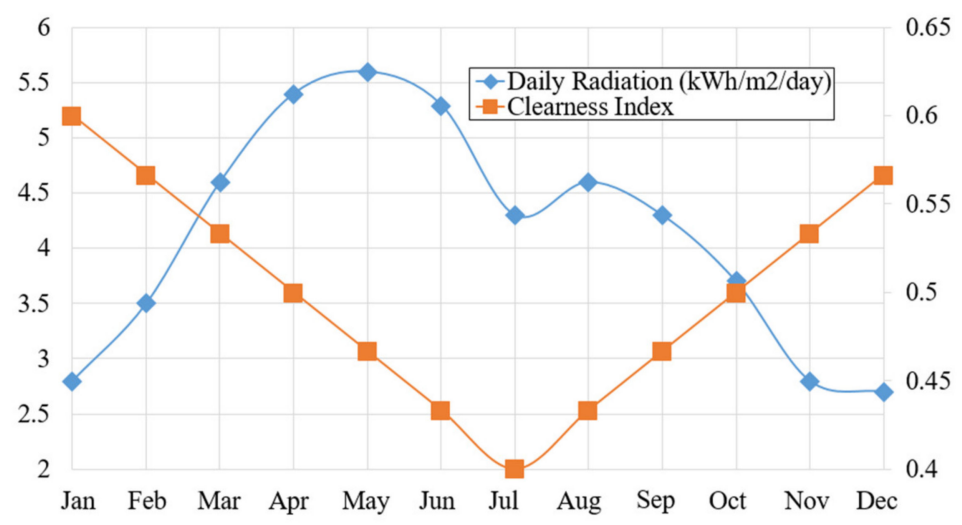

Figure 5. Monthly solar radiations at Deokjeok-do Island [13].

\subsection{HOMER Pro Simulation}

In the present study, the plan for renewable energy installed at Deokjeok-do Island is optimized using HOMER pro software (Hybrid Optimization Model for Electric Renewables) [26]. All the above-mentioned data such as load, wind and solar potential were inputted to HOMER pro. Table 1 presents the essential characteristics (technical as well as economic) of all the equipment selected for the present study.

Table 1. Selected Equipment.

\begin{tabular}{|c|c|c|c|c|c|}
\hline Equipment & Model & $\begin{array}{c}\text { Capital Cost } \\
(\$ / \mathbf{k W})\end{array}$ & $\begin{array}{l}\text { Replacement } \\
\text { Cost }(\$ / k W)\end{array}$ & $\begin{array}{c}\text { O\&M Cost } \\
\text { (\$/year) }\end{array}$ & $\begin{array}{c}\text { Lifetime } \\
\text { (years) }\end{array}$ \\
\hline Converter & $\begin{array}{c}\text { MTP-413F } \\
25 \mathrm{~kW}\end{array}$ & 800 & 800 & 10 & 10 \\
\hline Battery & $\begin{array}{l}\text { Surrette } \\
6 \text { CS25P }\end{array}$ & 250 & 250 & 1 & 20 \\
\hline PV Panel & CS6X-325P & 1500 & 1500 & 30 & 25 \\
\hline Wind Turbine & STX 93/2000 & $2,889,747$ & $2,889,747$ & 112,375 & 20 \\
\hline
\end{tabular}

It must be mentioned that equipment was selected after carefully following the guidelines provided by previous authors [13-22] except wind machine, which was shortlisted by adopting the technique recommended by the authors [27].

Leonics MTP-413F was selected as the converter as recommended by Busaidi et al. [28] and Akikur et al. [29] for medium-sized HRES such as generating electricity between 5 GWh to 10 GWh annually. This model was also recommended by Mandelli et al. [30] based on its low capital and replacement costs, respectively. Similarly, a kinetic model of battery (6CS25P) manufactured by Surrette is by far the most commonly used battery model for such type of feasibility studies due to its economic benefits (only 1 USD replacement cost). There are many different types of PV modules available but solar module named CS6X-325P manufactured by Canadian Solar Inc. is best suitable for Deokjeok-do due to its long lifetime (25 years) and high efficiency (20\%). Apart from the technical superiority of CS6X-325P over other PV modules. One other advantage is that this PV panel has a very low capital cost $(\$ 1.5 / \mathrm{W})$. Wind turbine model was selected according to the wind characteristics of Deokjeok-do and the detailed procedure can be found in the previous study by the authors [27].

Table 1 summarizes all the selected equipment modules and essential details.

Figure 6 displays the HOMER model developed for present work having separate transmission lines for direct current (DC) and alternate current (AC). 


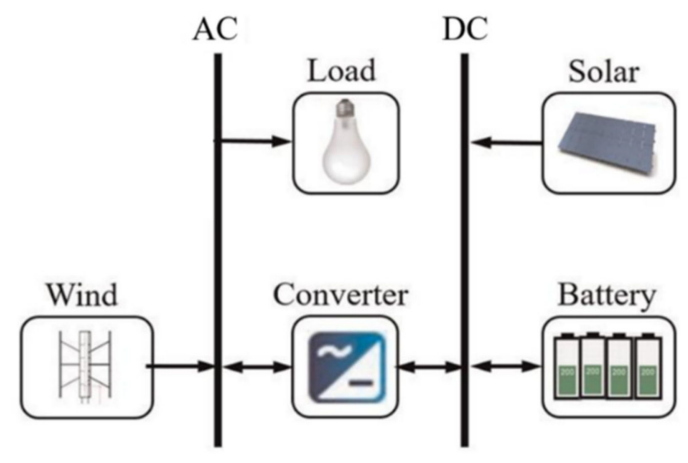

Figure 6. HOMER model [31].

\subsection{Pumped Hydro Storage (PHS) as Alternate Energy Storage System (ESS)}

Although HOMER pro only models batteries as default ESS, other types of ESSs can also be designed separately and compared with batteries. One of such energy storage systems is pumped hydro storage which is a mechanical type of ESS, as shown in Figure 1. Surplus electricity from HRES is consumed by a pump to lift the water in order to fill the upper reservoir (UR). On the other hand, the electricity deficit of HRES is compensated by running a hydro turbine, which uses stored water in UR. Lower reservoir (LR) can be a tank or it can also be some other natural water resource such as a river or sea, depending upon the geographical characteristics of the local site. In the current case, as Deokjeok-do is an island, so the sea will be considered as a lower reservoir.

In the customary PHS for coal-fired power plants or atomic plants, two water stores are required to be situated on the upper mountain and the lower valley. With the innovation improvement, seawater can now likewise be utilized as a lower water reservoir, especially in cases of remote islands where there will probably not be a sufficient new water source. Furthermore, remote islands are encompassed by the ocean, and in this way, geographical characteristics are also a reason to use seawater as the lower reservoir. The possibility of utilizing seawater for PHS was first analyzed by Japan [32], and a small power plant based on PHS as ESS was developed at Okinawa, with an approximate effectiveness of $77 \%$ [33].

\section{Modelling of PHS}

The accurate size determination of each component of PHS is significantly important in the designing process. The size of the pump must be greater than the maximum surplus electricity from HRES and similarly, the size of the hydro turbine must also be larger than the maximum electricity deficit. In the current case, there is no need to design LR, as stated above that LR will be the sea. Accurate size determination of UR is the most complex step in PHS designing process. For designing UR, pump flow rate $\left(q_{p}(t)\right)$ and hydro turbine flow rate $\left(q_{t}(t)\right)$ must be known at first place. Pump flow rate can be defined as follows [34]:

$$
q_{p}(t)=\frac{e_{p} P_{H R E S \rightarrow p}(t)}{\rho g h}=c_{p} \cdot P_{H R E S \rightarrow p}(t)
$$

where $e_{p}$ is overall pumping efficiency (0.5), $P_{\text {HRES } \rightarrow p}(t)$ is surplus power from HRES to pump, $\rho$ is water density $\left(1000 \mathrm{~kg} / \mathrm{m}^{3}\right), g$ is the acceleration due to gravity $\left(9.8 \mathrm{~m} / \mathrm{s}^{2}\right), h$ is UR height $(60 \mathrm{~m}$ assumed) and $c_{p}$ is called the water pumping coefficient $\left(3.06 \mathrm{~m}^{3} / \mathrm{kWh}\right)$, respectively. Similarly, the turbine flow rate can be defined as follows:

$$
q_{t}(t)=\frac{P_{t \rightarrow H R E S}(t)}{\rho g h e_{t}}=\frac{P_{t \rightarrow H R E S}(t)}{c_{t}}
$$


where $P_{t \rightarrow H R E S}(t)$ is the power from the hydro turbine to HRES, $e_{t}$ is turbine efficiency $(0.65)$ and $c_{t}$ is called the turbine generating coefficient $\left(0.106 \mathrm{kWh} / \mathrm{m}^{3}\right)$, respectively. Amount of water in UR at any time $t\left(Q_{U R_{t}}\right)$, can be estimated from the following equation:

$$
Q_{U R_{t}}=Q_{U R_{t-1}}(1-\alpha)+q_{p}(t)-q_{t}(t)
$$

where $\alpha$ is called the evaporation and leakage loss coefficient, which is assumed to be $10 \%$ for the current study. The cost of each component of PHS is estimated by using guidelines provided by T. Ma et al. [35].

\section{Results and Discussion}

This section will present the analysis on the basis of detailed technical and economic calculations and characteristics of the most ideal energy systems best-suited for Deokjeok-do. There were a total of 551,035 systems generated by HOMER pro simulations but the number of feasible systems solutions were limited to only 232,683 .

Out of all the feasible system solutions $(232,683)$, two systems (base cases) were selected as the most appropriate choice based on lowest possible net present cost (NPC) and lowest possible levelized cost of energy (LCOE). Both systems are defined as below:

- $\quad$ HRES A (base case): Energy system having lowest NPC

- HRES B (base case): Energy system having lowest LCOE

Table 2 shows the values of some variables for base cases (HRES A and HRES B) and for many other sensitivity cases. The values of sensitivity variables are selected in such a way that same numbers have been added and reduced from base values of variables as it is apparent from Table 2 as well. There can be multiple other combinations of sensitive variables which can be investigated, but that will make this study too lengthy and out of the scope of current purpose.

Table 2. Sensitivity Variables (HOMER Inputs).

\begin{tabular}{cccc}
\hline $\begin{array}{c}\text { Average Daily Electricity } \\
\text { Consumption (kWh/day) }\end{array}$ & $\begin{array}{c}\text { Interest Rate } \\
\mathbf{( \% )}\end{array}$ & $\begin{array}{c}\text { Project's Total Life } \\
\text { (Years) }\end{array}$ & Case \\
\hline 25,000 & 6 & 20 & Base \\
20,000 & 4 & 15 & Sensitivity \\
30,000 & 8 & 25 & Sensitivity \\
\hline
\end{tabular}

\subsection{Optimum HRESs with Battery as ESS}

Table 3 summarizes the essential characteristics of two optimal energy systems with batteries as the only option for energy storage. As batteries are one of the most expensive components of an HRES [32,34], so alternate ESS such as pumped hydro storage (PHS) will also be designed for both systems and costs will be compared with each other (Section 3.2). Net present cost (NPC) of energy system A is 11.3 million USD (lowest) whereas the lowest LCOE is $0.123 \mathrm{USD} / \mathrm{kWh}$ in case of energy system B. Table 3 conjointly displays the values of sensitivity variables at which optimum system solutions are obtained. Project lifetime of system A (15 years) is a smaller time period than that of system B (25 years), that's conjointly one amongst the explanations for low NPC of system A. Generally speaking, energy systems with low LCOE are preferred because of the fact that governments can support to reduce the overall NPC of the project via different subsidiary schemes related to renewable energy projects. So, relatively high NPC can be acceptable in some cases but high LCOE produces serious drawbacks related to the selection of the project. 
Table 3. Both HRES Planned.

\begin{tabular}{cccc}
\hline Variable & Unit & System A & System B \\
\hline NPC & Million $\$$ & 11.3 & 17.61 \\
LCOE & \$/kWh & 0.158 & 0.123 \\
Total Load Scaled & kWh/day & 20,000 & 20,000 \\
Average & per cent & 15 & 4 \\
Nominal Interest Rate & years & 15 & 25 \\
HRES Life &
\end{tabular}

Table 4 shows the total capacity of all equipment selected for system A and system B. Each HRES comprises of one wind turbine and almost $1000 \mathrm{~kW}$ capacity converter. Solar panel capacity of HRES B ( $3157 \mathrm{~kW})$ is larger than HRES A ( $2504 \mathrm{~kW})$, due to which the initial cost of HRES B is more than HRES A. One point must be mentioned here that by choosing a suitable wind turbine according to local wind characteristics, each HRES may have different system architectures as compared to the current scenario [17]. However, choosing a suitable wind turbine for any site requires a complex analysis involving extreme wind speed (EWS), turbulence intensity (TI) and local geographical characteristics, which are out of the scope of present work, so not performed here [22,27].

Table 4. Systems Architecture.

\begin{tabular}{ccccc}
\hline Component & Model & Unit & Size (System A) & Size (System B) \\
\hline PV Panels & CS6X-325P & $\mathrm{kW}$ & 2504 & 3157 \\
Battery & Surrette 6 CS 25P & strings & 7197 & 6269 \\
Wind Turbine & STX 93/2000 & ea. & 1 & 1 \\
System Converter & Leonics MTP-413F 25kW & $\mathrm{kW}$ & 1006 & 1009 \\
Dispatch Strategy & HOMER Cycle Charging & N/A & N/A & N/A \\
\hline
\end{tabular}

Adding different renewable energy resources such as biomass, tidal energy and food-waste to both systems, will definitely change the architecture of both systems as it is presented in Table 4. Doing so, may reduce the LCOE but will definitely increase the overall NPC. Such an investigations have not been performed here due to unavailability of such data at the local site. However, it is highly recommended to integrate as many renewable resources as available on the local site with the basic HRES just consisting of wind and solar energy.

Table 5 shows the summary of electricity production by each component and electricity consumption as well. As it is clear from the Table that PV panels are the main contributors of power generation in both cases. Both systems can independently fulfil all the electricity demand of Deokjeok-do Island, as it is also clear from Table 5 as well.

Table 5. Electricity Production Details.

\begin{tabular}{|c|c|c|c|c|c|}
\hline \multirow{2}{*}{$\begin{array}{l}\text { Electricity } \\
\text { Details }\end{array}$} & \multirow{2}{*}{ Unit } & \multicolumn{2}{|c|}{ System A } & \multicolumn{2}{|c|}{ System B } \\
\hline & & Value & $\begin{array}{l}\text { Percent of Total } \\
\text { Production }\end{array}$ & Value & $\begin{array}{l}\text { Percent of Total } \\
\text { Production }\end{array}$ \\
\hline PV production & kWh/annul & $5,173,542$ & 57.37 .30 & $5,969,810$ & 60.83 \\
\hline WT production & kWh/annual & $3,843,132$ & 42.62 & $3,843,132$ & 39.16 \\
\hline Total & kWh/annual & $9,016,674$ & 100.00 & $9,812,942$ & 100.00 \\
\hline Demand & kWh/annual & $7,296,369$ & 80.92 & $7,296,369$ & 74.35 \\
\hline Surplus & kWh/annual & $1,033,288$ & 11.46 & $1,821,884$ & 18.57 \\
\hline Unmet & kWh/annual & 3,631 & 0.04 & 3,676 & 0.04 \\
\hline
\end{tabular}

One shortcoming of the current study is that the simulated data shows results for only one year of electricity demand $(7,296,369 \mathrm{kWh})$. As the project is planned for 20 years, so it is not known whether the systems selected in Table 4 be able to fulfil all the electricity demands of the island or not for upcoming years? One way to address this issue will be probably to use the 'simulated electricity 
demand' data of the studied site. However, unfortunately, such data are also not available. So, it is assumed that electricity demand will remain fixed during all next 20 years. Although, the electricity demand selected $(7,296,369 \mathrm{kWh} /$ year $)$ in this study was the highest number for the last 20 years.

Figures 7 and 8 show the NPC and annualized costs of all the equipment of both system solutions, respectively. Both the figures indicate that solar panels are the most expensive equipment and also, their annual maintenance cost is the highest as well for both systems. Capital cost includes different type of costs occurred at the start of the project such as equipment cost, installation cost, labor cost and transportation costs. As it is clear from Figures 7 and 8 that capital cost is almost $70 \%$ of the total NPC and annual cost. The second type of cost is annually occurring operating and maintenance cost which includes workers' salaries, annual cleanliness cost, fuel cost and electricity cost to run the auxiliary equipment at the power plant. Replacement cost is used to buy new equipment during the project running time, once the lifetime of any equipment has finished, as shown in Table 1. Salvage are those benefits which are obtained by selling all the project equipment and other items after the project lifetime of 20 years. In Figures 7 and 8, positive cash flow represents costs and negative cash flow (salvage) are benefits.

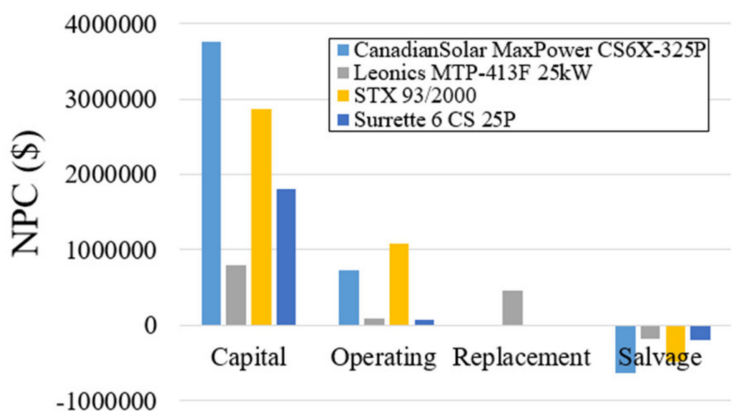

(a)

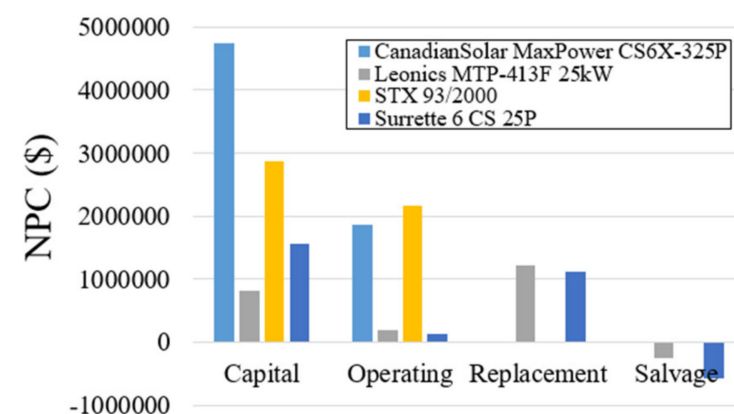

(b)

Figure 7. Net present cost (NPC) breakdown for both systems (a) System A (b) System B.

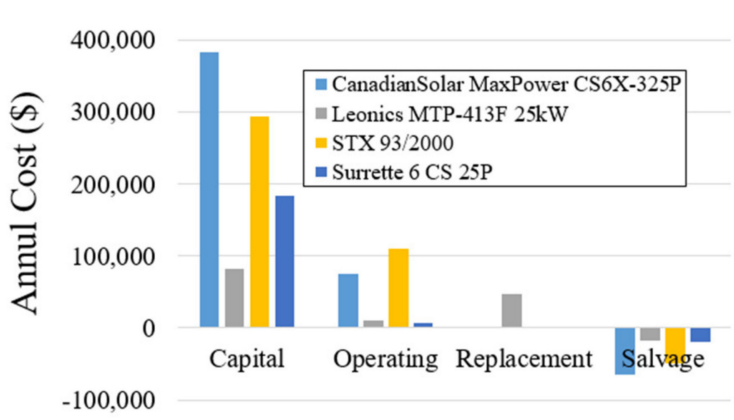

(a)

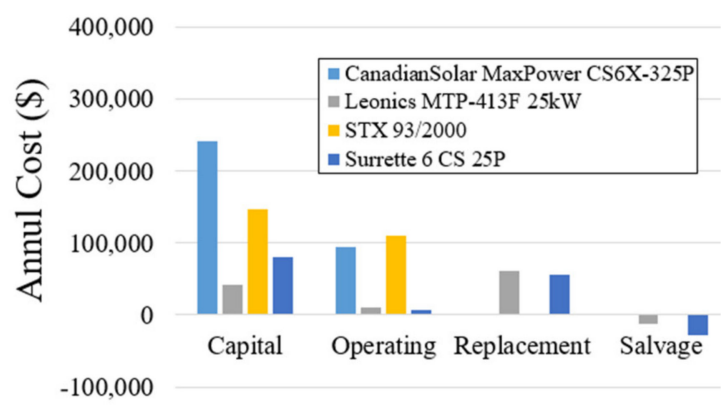

(b)

Figure 8. Annualised cost breakdown for both systems (a) System A (b) System B.

Figure 9 shows the impact of wind turbine hub height on the economics of both systems i.e., HRES A and HRES B (NPV is the net present value which is the difference between present values of benefits and costs, NPV $>0$ is must [27]). It is important to estimate the appropriate hub height as it has a direct effect on the electricity generated by wind turbine, which subsequently changes the values of NPV and LCOE. As the hub height increases, wind turbine rotor interacts with relatively higher wind speeds as compared to lower heights, which generates more electricity but, at the same time cost of tower increases and VICE VERSA for lower hub heights. So, it is a trade-off between more electricity and the cost of the tower. Figure 9 determines the optimal hub-height for each case. 

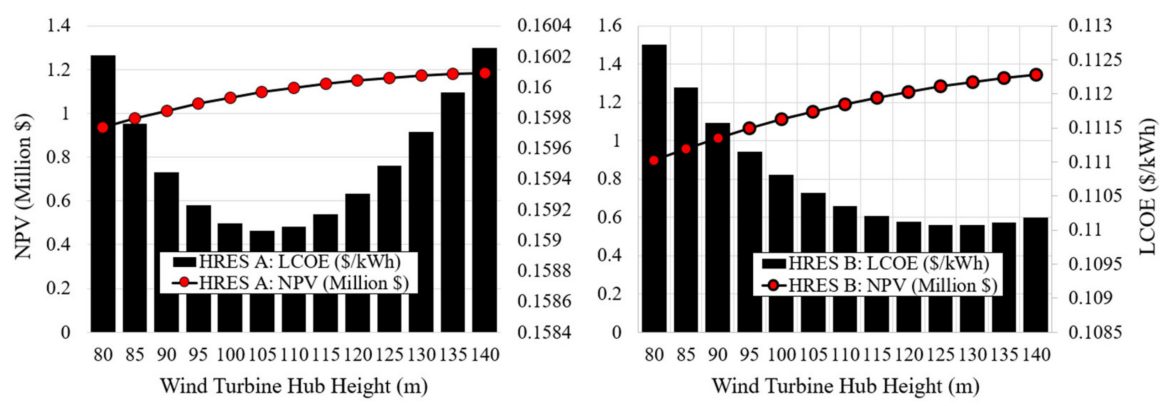

Figure 9. Effect of wind turbine hub height on the economics of both systems.

Finally, Table 6 shows the annual amount of pollutant gases emissions due to the operation of both systems.

Table 6. Pollutants Emission.

\begin{tabular}{cccc}
\hline Pollutant & Unit & System A & System B \\
\hline $\mathrm{CO}_{2}$ & $\mathrm{~kg} /$ annum & 795 & 700 \\
$\mathrm{CO}$ & $\mathrm{kg} /$ annum & 8.83 & 7.77 \\
Unburned Hydrocarbons & $\mathrm{kg} /$ annum & 0 & 0 \\
Particulate Matter & $\mathrm{kg} /$ annum & 0 & 0 \\
$\mathrm{SO}_{2}$ & $\mathrm{~kg} /$ annum & 0 & 0 \\
$\mathrm{NO}_{\mathbf{x}}$ & $\mathrm{kg} /$ annum & 5.52 & 4.86 \\
\hline
\end{tabular}

\subsection{Optimum HRESs with PHS as ESS}

HOMER Pro software automatically considers batteries as default ESS for storing surplus electricity from HRES. However, batteries are one of the most expensive components of any HRES [18]. Therefore, it was decided to design an alternate ESS such as PHS and compare the results with batteries on economic grounds. Table 7 shows the values of all important parameters related to the designed PHS for both optimal HRESs. The technical and economical methodologies for preparing Table 7 have already been covered in Section 2.4 respectively and can also be found in reference [34]. Both systems have equal sizes of hydro turbines, whereas the size of the pump is slightly higher in case of system B. Table 7 also shows the amount of water that must be put inside UR at $t=0$ (even before the start of operation). This is due to the fact that at the start of operation (during few early days) there will always be electricity deficit in case of both systems, therefore, it will require additional electricity from the hydro turbine to successfully fulfil the electricity demand of Deokjeok-do Island. It is also clear from Table 7 that PHS is slightly cheaper than batteries in terms of initial investment for both optimal system solutions.

Table 7. Pumped hydro storage (PHS) Design for Both Systems.

\begin{tabular}{cccc}
\hline Parameter & Unit & System A & System B \\
\hline $\begin{array}{c}\text { Maximum hourly deficit of } \\
\text { electricity during the year } \\
\text { Size of hydro turbine }\end{array}$ & $\mathrm{kW}$ & 1005 & 1009 \\
Maximum hourly surplus & $\mathrm{kW}$ & 1020 & 1020 \\
electricity during the year & $\mathrm{kW}$ & 3578 & 4211 \\
Size of pump & $\mathrm{kW}$ & 3600 & 4220 \\
UR size & $\mathrm{m}^{3}$ & 229,770 & 255,300 \\
Minimum level of water in UR & $\mathrm{m}^{3}$ & 275,72 & 459,54 \\
Date of min. water level in UR & date & $12 / 20 / 201711: 00: 00$ & $10 / 29 / 20177: 00: 00$ \\
Amount of water in UR at t $=$ & $\mathrm{m}^{3}$ & 528,47 & 199,134 \\
Capital Cost of hydro turbine & Million \$ & 0.612 & 0.612 \\
Capital Cost of pump & Million \$ & 0.49 & 0.58 \\
Capital Cost of UR & Million \$ & 0.22977 & 0.2553 \\
Total capital cost of PHS & Million \$ & 1.33497 & 1.44544 \\
Total capital cost of battery bank & Million \$ & 1.8012 & 1.575 \\
\hline
\end{tabular}


Figure 10 shows the amount of water in UR throughout the year for both systems A and B. During the summer season UR is almost fully filled with water for system A whereas it is winter season for system B. On average basis, water level in UR is less than $50 \%$ for 252 days in case of system A and it is 298 days for system B. Minimum levels of water in UR for both systems have already been mentioned in Table 7. One of the reasons for very low water level during winter and summer seasons (in case of HRES A and HRES B respectively) is due to the high consumption of electricity during these days. In South Korea, during the winter season, the minimum temperature passes below $-15^{\circ} \mathrm{C}$ which requires relatively more electrical energy for heating the indoors of buildings, resulting in high-demand of electricity. Similar conditions can be associated with the summer season in terms of cooling the indoors of buildings. Although Figure 10 just shows the water level in UR at any time of the year, this behavior can be associated with the demand for electricity during the year. The trends are different in both cases mainly due to the different architecture of both systems as shown in Table 4.

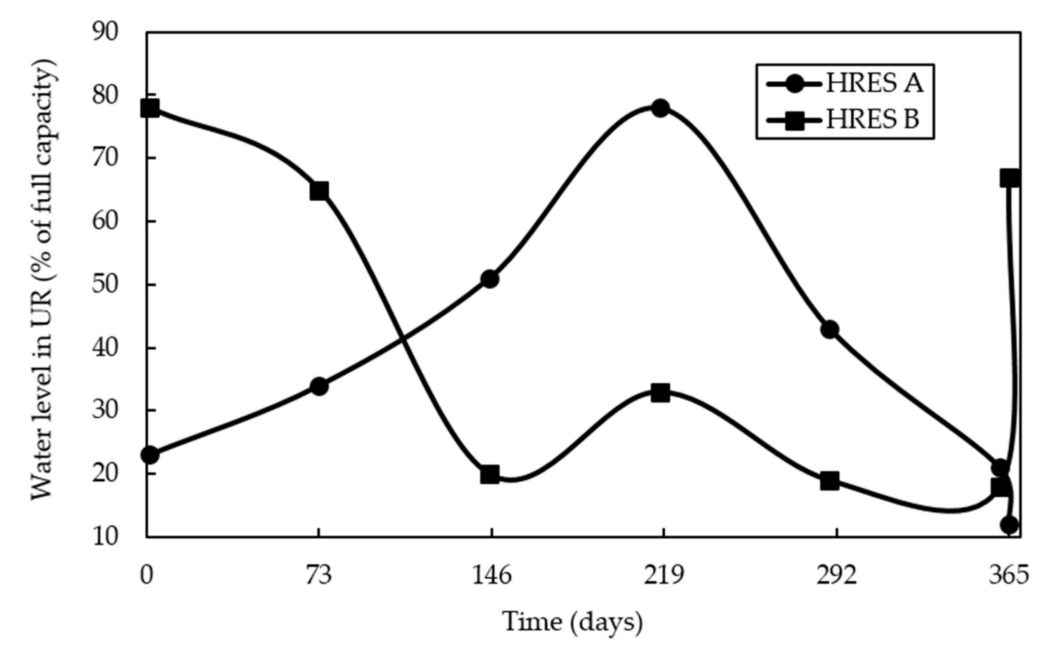

Figure 10. Amount of water in UR.

\subsection{Sensitivity Cases}

In spite of the fact that the most ideal framework arrangements have just been clarified in detail in the above segments. In any case, it is additionally of basic significance to quickly explain a portion of the other alternate framework arrangements based on economic assessments. So, as to accomplish this objective, Figure 11 has been readied, which demonstrates numerous framework arrangements acquired by superimposing NPC over LCOE. Figure 11 demonstrates an aggregate of 81 ideal framework solutions obtained by varying the values of all sensitivity referenced in Table 2. 


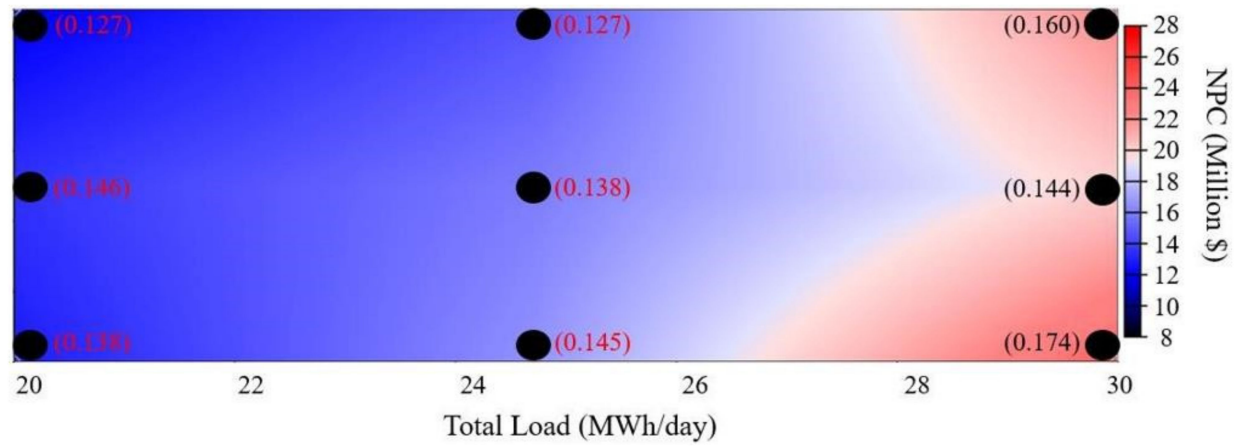

(a)

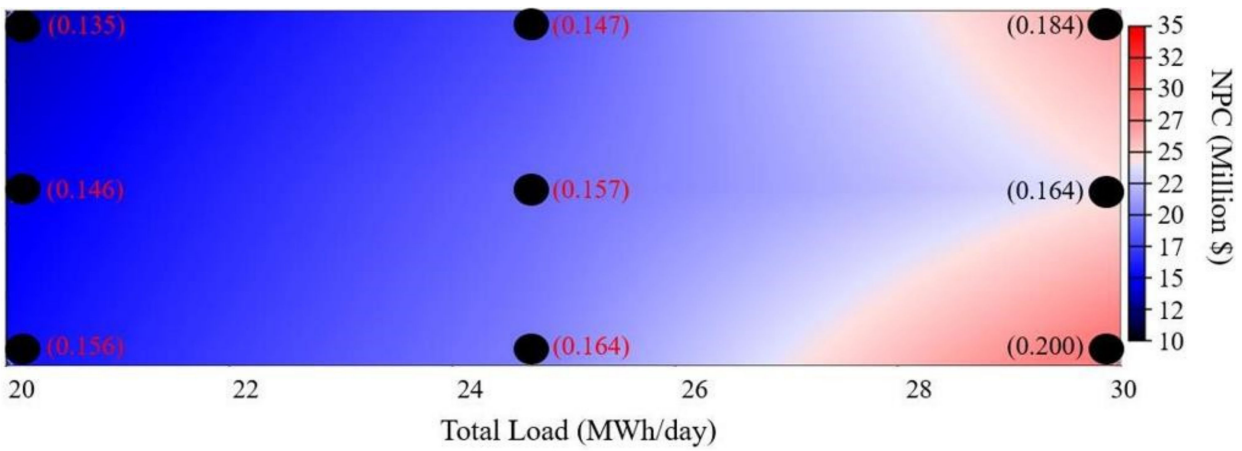

(b)

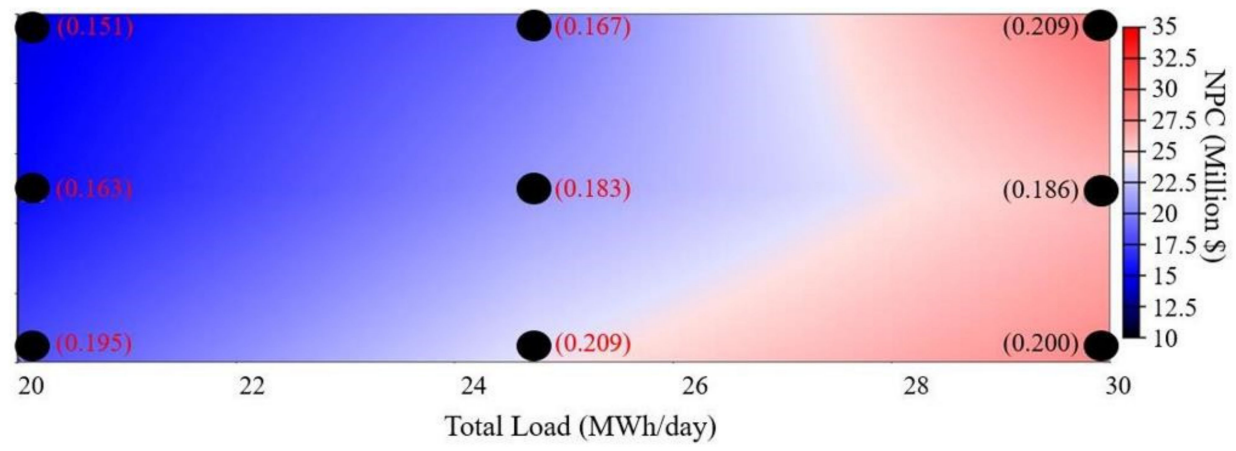

(c)

Figure 11. Feasible HRES solutions with NPC superimposed over levelized cost of energy (LCOE) (a) Interest rate: 4\%; HRES Life: 15 years (b) Interest rate: 6\%; HRES Life: 20 years (c) Interest rate: 8\%; HRES Life: 25 years.

\section{Conclusions}

The current study aimed to design and optimize an off-grid hybrid renewable energy system (HRES) for a remote island of South Korea, where no other means of power generation are available. The study considered two different types of renewable energy resources, namely wind and solar. Two of the most suitable HRESs were recommended based upon the lowest NPC (System A) and LCOE (System B), respectively.

The daily mean AC load was estimated to be 24,720 kWh with $2292 \mathrm{~kW}$ as peak load, which occurs typically during the winter season. Annual mean wind speed was measured to be $3.6 \mathrm{~m} / \mathrm{s}(10 \mathrm{~m}$ height) with $4.13 \mathrm{kWh} / \mathrm{m}^{2}$ as daily solar radiations. The total net present cost for energy system A was estimated to be 11.3 million \$ whereas for energy system B, it corresponds to a slightly higher value i.e., 
17.6 million \$. However, cost of electricity for energy system A is relatively higher than energy system $B$ as it is $0.159 \$ / \mathrm{kWh}$ for energy system A and $0.122 \$ / \mathrm{kWh}$ for energy system B. Both systems consist of one STX 93/2000 wind turbine and $2504 \mathrm{~kW}$ PV panels (System A) and $3157 \mathrm{~kW}$ PV panels (System B). The annual electricity demand of the island is $7,296,369 \mathrm{kWh}$. System A can produce $9,016,674$ $\mathrm{kWh} /$ year whereas system B can produce 9,812,942 kWh/year. The study also designed the pumped hydro storage (PHS) to deal with the surplus and deficit of electricity for both systems and compared the economics with the battery as well. The analysis showed that PHS can be a cheaper choice as the total capital cost for constructing PHS was estimated to be 1.34 million USD for system A (1.80 million USD for battery) and 1.45 million USD for system B (1.58 million USD for battery). Apart from above-mentioned system solutions, NPC and LCOE of multiple other systems were also estimated by varying the values of input variables such as discount rate, project lifetime and daily load.

Author Contributions: All data were collected and analyzed by S.A. who also devised the methodology and wrote the manuscript. C.-M.J. provided his guidance and supervision for this study. All authors have read and agreed to the published version of the manuscript.

Funding: This study was funded by major project funding from the Korea Institute of Civil Engineering and Building Technology [grant number 20200034-001].

Conflicts of Interest: The authors declare no actual or potential conflicts of interest.

\section{References}

1. IEA. Measuring Progress Towards Energy for All: Power to the People? In World Energy Outlook 2012; [Chapter 18]; International Energy Agency: Paris, France, 2012.

2. Upadhyay, S.; Sharma, M.P. A review on configurations, control and sizing methodologies of hybrid energy systems. Renew. Sustain. Energy Rev. 2014, 38, 47-63. [CrossRef]

3. Eriksson, E.L.V.; Gray, E.M. Optimization and integration of hybrid renewable energy hydrogen fuel cell energy systems-A critical review. Appl. Energy 2017, 202, 348-364. [CrossRef]

4. Khare, V.; Nema, S.; Baredar, P. Solar-wind hybrid renewable energy system: A review. Renew. Sustain. Energy Rev. 2016, 58, 23-33. [CrossRef]

5. Balamurugan, P.; Ashok, S.; Jose, T.L. Optimal operation of biomass/wind/PV hybrid energy system for rural areas. Int. J. Green Energy 2009, 6, 104-116. [CrossRef]

6. Goel, S.; Sharma, R. Performance evaluation of stand-alone, grid connected and hybrid renewable energy systems for rural application: A comparative review. Renew. Sustain. Energy Rev. 2017, 78, 1378-1389. [CrossRef]

7. Perez-Navarro, A.; Alfonso, D.; Álvarez, C.; Ibáñez, F.; Sanchez, C.; Segura, I. Hybrid biomass-wind power plant for reliable energy generation. Renew. Energy 2010, 35, 1436-1443. [CrossRef]

8. Borhanazad, H.; Mekhilef, S.; Saidur, R.; Boroumandjazi, G. Potential application of renewable energy for rural electrification in Malaysia. Renew. Energy 2013, 59, 210-219. [CrossRef]

9. Zuberi, M.J.S.; Torkmahalleh, M.A.; Ali, S.H. A comparative study of biomass resources utilization for power generation and transportation in Pakistan. Int. J. Hydrog. Energy 2015, 40, 11154-11160. [CrossRef]

10. Bhandari, B.; Lee, K.T.; Lee, C.S.; Song, C.K.; Maskey, R.K.; Ahn, S.H. A novel off-grid hybrid power system comprised of solar photovoltaic, wind, and hydro energy sources. Appl. Energy 2014, 133, 236-242. [CrossRef]

11. Mazzola, S.; Astolfi, M.; Macchi, E. The potential role of solid biomass for rural electrification: A techno economic analysis for a hybrid micro grid in India. Appl. Energy 2016, 169, 370-383. [CrossRef]

12. Ahmad, J.; Imran, M.; Khalid, A.; Iqbal, W.; Ashraf, S.R.; Adnan, M.; Khokhar, K.S. Techno economic analysis of a wind-photovoltaic-biomass hybrid renewable energy system for rural electrification: A case study of Kallar Kahar. Energy 2018, 148, 208-234. [CrossRef]

13. Baek, S.; Park, E.; Kim, M.G.; Kwon, S.J.; Kim, K.J.; Ohm, J.Y.; del Pobil, A.P. Optimal renewable power generation systems for Busan metropolitan city in South Korea. Renew. Energy 2016, 88, 517-525. [CrossRef]

14. Baek, S.; Kim, H.; Chang, H. Optimal hybrid renewable airport power system: Empirical study on Incheon International Airport, South Korea. Sustainability 2016, 8, 562. [CrossRef]

15. Baek, S.; Kim, H.; Chang, H. Optimal hybrid renewable power system for an emerging Island of South Korea: The case of Yeongjong Island. Sustainability 2015, 7, 13985-14001. [CrossRef] 
16. Kim, H.; Baek, S.; Park, E.; Chang, H.J. Optimal green energy management in Jeju, South Korea-On-grid and off-grid electrification. Renew. Energy 2014, 69, 123-133. [CrossRef]

17. Park, E.; Kwon, S.J. Renewable electricity generation systems for electric-powered taxis: The case of Daejeon metropolitan city. Renew. Sustain. Energy Rev. 2016, 58, 1466-1474. [CrossRef]

18. Park, E.; Kwon, S.J. Towards a Sustainable Island: Independent optimal renewable power generation systems at Gadeokdo Island in South Korea. Sustain. Cities Soc. 2016, 23, 114-118. [CrossRef]

19. Yoo, K.; Park, E.; Kim, H.; Ohm, J.; Yang, T.; Kim, K.; del Pobil, A. Optimized renewable and sustainable electricity generation systems for Ulleungdo Island in South Korea. Sustainability 2014, 6, 7883-7893. [CrossRef]

20. Oh, S.D.; Yoo, Y.; Song, J.; Song, S.J.; Jang, H.N.; Kim, K.; Kwak, H.Y. A cost-effective method for integration of new and renewable energy systems in public buildings in Korea. Energy Build. 2014, 74, 120-131. [CrossRef]

21. Park, E. Potentiality of renewable resources: Economic feasibility perspectives in South Korea. Renew. Sustain. Energy Rev. 2017, 79, 61-70. [CrossRef]

22. Ali, S.; Lee, S.M.; Jang, C.M. Statistical analysis of wind characteristics using Weibull and Rayleigh distributions in Deokjeok-do Island-Incheon, South Korea. Renew. Energy 2018, 123, 652-663. [CrossRef]

23. Shin, Y.; Koo, W.Y.; Kim, T.H.; Jung, S.; Kim, H. Capacity design and operation planning of a hybrid PV-wind-battery-diesel power generation system in the case of Deokjeok Island. Appl. Therm. Eng. 2015, 89, 514-525. [CrossRef]

24. Korean Meteorological Administration (KMA). Available online: https://data.kma.go.kr/ (accessed on 28 September 2018).

25. Nematollahi, O.; Kim, K.C. A feasibility study of solar energy in South Korea. Renew. Sustain. Energy Rev. 2017, 77, 566-579. [CrossRef]

26. Homer Pro Software. Available online: https://www.homerenergy.com/products/pro/index.html (accessed on 28 September 2018).

27. Ali, S.; Lee, S.M.; Jang, C.M. Techno-economic assessment of wind energy potential at three locations in South Korea using long-term measured wind data. Energies 2017, 10, 1442. [CrossRef]

28. Al Busaidi, A.S.; Kazem, H.A.; Al-Badi, A.H.; Khan, M.F. A review of optimum sizing of hybrid PV-Wind renewable energy systems in Oman. Renew. Sustain. Energy Rev. 2016, 53, 185-193. [CrossRef]

29. Akikur, R.K.; Saidur, R.; Ping, H.W.; Ullah, K.R. Comparative study of stand-alone and hybrid solar energy systems suitable for off-grid rural electrification: A review. Renew. Sustain. Energy Rev. 2013, 27, 738-752. [CrossRef]

30. Mandelli, S.; Barbieri, J.; Mereu, R.; Colombo, E. Off-grid systems for rural electrification in developing countries: Definitions, classification and a comprehensive literature review. Renew. Sustain. Energy Rev. 2016, 58, 1621-1646. [CrossRef]

31. Ali, S.; Jang, C.M. Evaluation of PV-Wind Hybrid Energy System for a Small Island. In Wind Solar Hybrid Renewable Energy System; IntechOpen: London, UK, 2019.

32. Li, R.; Wu, B.; Li, X.; Zhou, F.; Li, Y. Design of wind-solar and pumped-storage hybrid power supply system. In Proceedings of the 2010 3rd International Conference on Computer Science and Information Technology, Chengdu, China, 9-11 July 2010; Volume 5, pp. 402-405.

33. Brown, P.D.; Lopes, J.P.; Matos, M.A. Optimization of pumped storage capacity in an isolated power system with large renewable penetration. IEEE Trans. Power Syst. 2008, 23, 523-531. [CrossRef]

34. Ma, T.; Yang, H.; Lu, L.; Peng, J. Technical feasibility study on a standalone hybrid solar-wind system with pumped hydro storage for a remote Island in Hong Kong. Renew. Energy 2014, 69, 7-15. [CrossRef]

35. Ma, T.; Yang, H.; Lu, L. Feasibility study and economic analysis of pumped hydro storage and battery storage for a renewable energy powered Island. Energy Convers. Manag. 2014, 79, 387-397. [CrossRef]

(C) 2020 by the authors. Licensee MDPI, Basel, Switzerland. This article is an open access article distributed under the terms and conditions of the Creative Commons Attribution (CC BY) license (http://creativecommons.org/licenses/by/4.0/). 